Article

\title{
Rapid Fabrication of Chemical Solution-Deposited Lanthanum Nickelate Thin Films via Intense Pulsed-Light Process
}

\author{
Junghum Park ${ }^{1} \mathbb{C}$, Yonghyun Lim ${ }^{1}$, Seokwon Kong ${ }^{1}$, Hojae Lee ${ }^{1}$ and Young-Beom Kim ${ }^{1,2, *}$ \\ 1 Department of Mechanical Convergence Engineering, Hanyang University, Seoul 133-791, Korea; \\ junghum93@hanyang.ac.kr (J.P.); shskt2002@gmail.com (Y.L.); aflhzv@naver.com (S.K.); \\ ehz123@hanyang.ac.kr (H.L.) \\ 2 Institute of Nano Science and Technology, Hanyang University, Seoul 133-791, Korea \\ * Correspondence: ybkim@hanyang.ac.kr; Tel.: +82-2-2220-0544; Fax: +82-2-2220-2299
}

Received: 17 May 2019; Accepted: 5 June 2019; Published: 8 June 2019

\begin{abstract}
In this paper, we demonstrate the practicality and feasibility of the flash light-sintering method to fabricate the ceramic material perovskite structure for lanthanum nickel oxide $\left(\mathrm{LaNiO}_{3}\right.$; LNO) thin films using flash light irradiation equipment. LNO thin films are deposited on an Si wafer and $\mathrm{Al}_{2} \mathrm{O}_{3}$ substrate via the chemical solution deposition (CSD) method and sintered by a thermal and flash light-irradiation process with a bottom heater. The properties of flash light-sintered LNO thin films are compared with those of thermally sintered films. The surface morphology, crystal development, and electric conductivity of the LNO thin films are measured by field-emission scanning electron microscope (FE-SEM), X-ray diffraction (XRD), and a four-point probe, respectively. Flash light sintering was accomplished in milliseconds. Through the comparison of thermal sintering and flash light-sintering results, it was confirmed that perovskite LNO thin films deposited by the CSD method can be fabricated by flash light sintering. We show that the flash light sintering method can solve several inherent issues of the conventional thermal sintering method.
\end{abstract}

Keywords: perovskite material; chemical solution deposition; functional thin films; flash light irradiation

\section{Introduction}

The $\mathrm{ABO}_{3}$ perovskite structured ceramic materials have been studied as functional materials in various energy conversion and storage devices, including solid oxide fuel cells, ferroelectric capacitors, and piezoelectric power generators. These oxide materials have been studied over the past few decades in various disciplines with respect to the suitability of properties for energy device applications such as high catalytic activity for oxygen reduction, electric conductivity, and microstructural stability [1-9]. Since various ions can be structurally located in the perovskite structure, this material exhibits special characteristics, as mentioned above, which depend on the variety of cations located at the $\mathrm{A}$ and $\mathrm{B}$ sites, e.g., $\mathrm{La}_{1-x} \mathrm{Sr}_{x} \mathrm{CoO}_{3-d}, \mathrm{La}_{1-x} \mathrm{Sr}_{x} \mathrm{MnO}_{3-d}, \mathrm{LaNiO}_{3}$, and $\mathrm{La}_{1-x} \mathrm{Sr}_{x} \mathrm{C}_{0.5} \mathrm{~F}_{0.5}$. In the perovskite structure, larger cations occupy the A site on the corners, and smaller $\mathrm{B}$ site cations are located at the center of the body. The oxygen ions are located at the centers of the faces. Since perovskite structures can accept various materials at the A and B sites as dopants, this diversity can provide improved specific properties for application such as electronic and ionic conductivity and material stability [10-15]. Rare earth $\mathrm{ABO}_{3}$ perovskite oxide materials $(R=\mathrm{La}, \mathrm{Pr}, \mathrm{Nd}, \mathrm{Sm})$ have superior material properties, and lanthanum nickel oxide $\left(\mathrm{LaNiO}_{3}, \mathrm{LNO}\right)$ is an especially promising functional oxide material. Since LNO contains the rare earth element lanthanum and three-dimensional (3D) transition metals $\mathrm{Ni}^{3+}$ 
at the A and B sites, respectively, it has high electronic conductivity at room temperature and shows superior catalytic properties [16]. Also, while other lanthanum perovskite oxides contain strontium and cobalt, which can generate a secondary phase with some materials and decrease the performance at elevated temperature, LNO has better chemical stability. In addition, the catalytic activity for oxygen reduction is as high as that of a platinum catalyst [17]. Therefore, LNO perovskites have been investigated as a functional oxide layer in various applications for superior chemical and electrical properties [18-24].

Perovskite oxide thin films can be synthesized by various thin film deposition methods and categorized into vacuum and non-vacuum processes. Vacuum deposition processes can be divided into physical vapor deposition (PVD) processes such as pulsed laser deposition (PLD) and sputtering and chemical vapor deposition (CVD) processes including atomic layer deposition (ALD) [24,25]. Despite their precise thickness and composition control capability, there are several issues for vacuum processes, such as relatively low productivity and high process cost. On the other hand, the non-vacuum processes are comparably simple, inexpensive, and highly productive, since they do not require a complex vacuum environment. Chemical solution deposition (CSD) has many advantages such as its large-area production of high-quality crystalline films, easy stoichiometric control, and relatively low fabrication cost [26,27].

Regardless of the deposition technique, high-temperature thermal treatment is essential to obtain the desired material properties. Chemical solution-deposited films were sintered at a relatively low temperature due to the use of metal organic precursors, shorter chain organic species, and lower boiling point solvents. However, the deposited amorphous films should traditionally be exposed at high temperature $\left(\sim 700^{\circ} \mathrm{C}\right)$ to develop crystallinity by the nucleation and growth process to obtain the desired material properties such as electrical conductivity and electrochemical activity. These conventional sintering methods require a long process time to increase the temperature and cooling without breakage of the sintered films. The long process time is directly related to the process cost, and can be an obstacle for the commercialization of the devices. To resolve these issues, various research efforts have utilized alternative methods such as laser, microwave, and light sintering processes. The flash light sintering method has been studied since it can dramatically decrease the total process time to a few seconds when it sinters metals such as $\mathrm{Cu}$ and $\mathrm{Ag}$ under standard pressure and temperature conditions [28-31]. However, studies on the flash light sintering of ceramic materials is relatively insufficient. The flash light irradiation technique uses white flash light in the visible wavelength range from 380 to $980 \mathrm{~nm}$ via a xenon lamp. The precise dose of total energy density $\left.\mathrm{J} / \mathrm{cm}^{2}\right)$ transferred to the target can be controlled by a set on time and off time for light irradiation. Since the energy transfer is performed instantaneously through light irradiation, this novel light sintering process significantly decreases the total process time and can be considered an economical process compared to the conventional thermal sintering method.

In this study, we fabricated lanthanum nickel oxide (LNO) perovskite thin films by the CSD method and adopted the novel flash light irradiation method for the post-heat treatment process. Compared to the conventional annealing process, which easily requires tens of hours including cooling time, the process time was reduced to several seconds with this novel method. After the fabrication of the film, material properties such as microstructure and crystallinity were investigated. In addition, the electrical properties of the films were observed by measuring and comparing the resistivity of the films with those fabricated by the conventional thermal sintering method. We believe that these results provide implications to lower the fabrication time and cost as well as facilitate the commercialization of devices that require thin perovskite ceramic films.

\section{Experiment}

The precursor solution was synthesized using the metal organic precursors $\mathrm{La}\left(\mathrm{NO}_{3}\right)_{3} \cdot 6 \mathrm{H}_{2} \mathrm{O}$ and $\mathrm{Ni}\left(\mathrm{CH}_{3} \mathrm{COO}\right)_{2} \cdot 4 \mathrm{H}_{2} \mathrm{O}$ as starting materials, 2-methoxy ethanol (MOE) as a solvent, and acetylacetone (Acac) as the chelating agent. $\mathrm{La}\left(\mathrm{NO}_{3}\right)_{3} \cdot 6 \mathrm{H}_{2} \mathrm{O}$ and $\mathrm{Ni}\left(\mathrm{CH}_{3} \mathrm{COO}\right)_{2} \cdot 4 \mathrm{H}_{2} \mathrm{O}$ were dissolved in 2-methoxy ethanol and stirred at $115^{\circ} \mathrm{C}$ for $15 \mathrm{~min}$. The two solutions were cooled to $80^{\circ} \mathrm{C}$ and reheated to $115^{\circ} \mathrm{C}$ 
after mixing. The detailed solution manufacturing method is depicted in Figure 1. The lanthanum and nickel metal molar ratio was $\mathrm{La}: \mathrm{Ni}=1: 1$. Acetylacetone was added to the mixture and stirred at $115^{\circ} \mathrm{C}$ for $30 \mathrm{~min}$. The mixed solution was stirred at $60^{\circ} \mathrm{C}$ for $2.5 \mathrm{~h}$, cooled at room temperature, and stirred for $2.5 \mathrm{~h}$ before deposition [32]. The final molar ratio of solution was La:Ni:MOE:Acac = 1:1:50:2 [23]. The metal precursor solution concentration was $0.4 \mathrm{M}$.

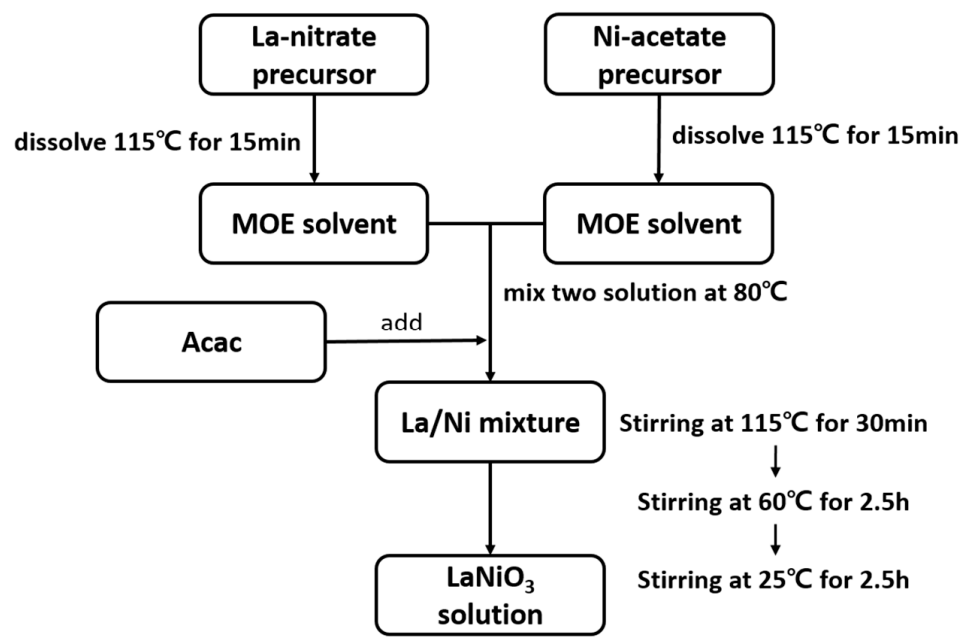

Figure 1. Flow chart of fabricating $\mathrm{LaNiO}_{3}$ precursor solution.

The solution was spin-coated on a $\mathrm{Si}(100)$ and $\mathrm{Al}_{2} \mathrm{O}_{3}$ substrate at $2500 \mathrm{rpm}$ for $30 \mathrm{~s}$. The deposited LNO was dried at $350{ }^{\circ} \mathrm{C}$ for $5 \mathrm{~min}$. The films were heat-treated by both conventional thermal furnace and flash light irradiation. Thermal sintering was conducted at temperatures in the range from 700 to $1100{ }^{\circ} \mathrm{C}$ for $2 \mathrm{~h}$ under the air atmosphere, and it was carried out in two steps. The temperature was increased relatively quickly at a ramp rate of $5{ }^{\circ} \mathrm{C} / \mathrm{min}$ to $500{ }^{\circ} \mathrm{C}$ and maintained for $1 \mathrm{~h}$ to decompose the organics in the solution. Then, the temperature was increased at a slower ramp rate of $1{ }^{\circ} \mathrm{C} / \mathrm{min}$ to the final heat treatment temperature, and the deposited films were sintered for $2 \mathrm{~h}$ to obtain the desired perovskite phases [33]. The light sintering process was carried out with a bottom heater to supply heat energy to the LNO films. The temperatures of the bottom heater and substrate were maintained at $500{ }^{\circ} \mathrm{C}$ during flash light irradiation. The flash light sintering conditions were controlled by the on-time (irradiation time per pulse), off-time (interval time between pulses), number of pulses (\#), and total energy density per pulse $\left(\mathrm{J} / \mathrm{cm}^{2}\right)$, as depicted in Figure 2. Therefore, we measured the total energy density using a power meter (Nova II, People Laser Tech Inc., Anyang, South Korea). In the main sintering step, the total energy density was varied from 60 to $130 \mathrm{~J} / \mathrm{cm}^{2}$ for six pulses, with an on-time of $30 \mathrm{~ms}$ and an off-time of $80 \mathrm{~ms}$. The total flash light irradiation time was $580 \mathrm{~ms}$, and the irradiation distance between the xenon lamp and sample was $6 \mathrm{~mm}$.



Figure 2. Schematic of the flash light irradiation time with on and off time. 
The material properties of surface and cross-sectional morphology and crystal development and the electrical property of sheet resistance of the LNO films sintered by thermal and light irradiation were analyzed. We used field emission scanning electron microscopy (FE-SEM; JSM-6701F, JEOL Ltd., Akishima, Japan) and X-ray diffraction (XRD; D8-Advance, Bruker, Billerica, MA, USA) for material characterization. The DC 4-probe method used a Keithley 2400 source meter (Keithley Instruments Inc., Cleveland, OH, USA) for electrical property analysis at room temperature.

\section{Results and Discussion}

The microstructure and thickness of the thermally sintered LNO films were analyzed by FE-SEM. Surface and cross-sectional images of the thermal sintered LNO thin film layers are shown in Figure 3. The CSD method has the advantages of a uniform thin film quality with a constant deposition thickness and relatively low sintering temperature. We obtained about 250-nm thick LNO films by repeating the spin coating process, as shown in Figure 3f, where the uniform and flat layers seem to have good connectivity between laminated layers. To investigate the effect of sintering temperature on surface morphology, the LNO thin films were sintered at $700-1100{ }^{\circ} \mathrm{C}$. A nanoporous structure may arise from the decomposition of organic residues. When thermal energy was applied at the beginning of the process, the pores and grains appeared. As the sintering temperature increases, the grains can be identified and grow in FE-SEM images. The LNO thin films become porous at $700-900{ }^{\circ} \mathrm{C}$ and gradually show grain growth, resulting in a dense film, as described in Figure 3. As the sintering temperature increases, grain growth in the LNO thin films is observed. The surface morphology of the sintered film at $700{ }^{\circ} \mathrm{C}$ (Figure 3a) has tens of nanometer-sized pores and nanoscale grains as the necking of particles. It seems that the film surface sintered at $800{ }^{\circ} \mathrm{C}$ (Figure $3 \mathrm{~b}$ ) showed grain growth and increased pore size compared to that sintered at $700{ }^{\circ} \mathrm{C}$. Figure $3 \mathrm{c}$ of the film surface sintered at $900{ }^{\circ} \mathrm{C}$ confirms that grain growth due to the increase in sintering temperature was prominent, and that the area of overall pores decreased from 700 to $900{ }^{\circ} \mathrm{C}$. Furthermore, when the LNO thin films were sintered at 1000 and $1100{ }^{\circ} \mathrm{C}$, the pores disappeared due to grain growth (Figure 3d,e). Surface morphology analysis viewed via FE-SEM showed that, as the sintering temperature increased, we confirmed that the porosity and the grain growth on the surfaces decreased. In addition, necking between particles increased, and grains were observed due to growth.

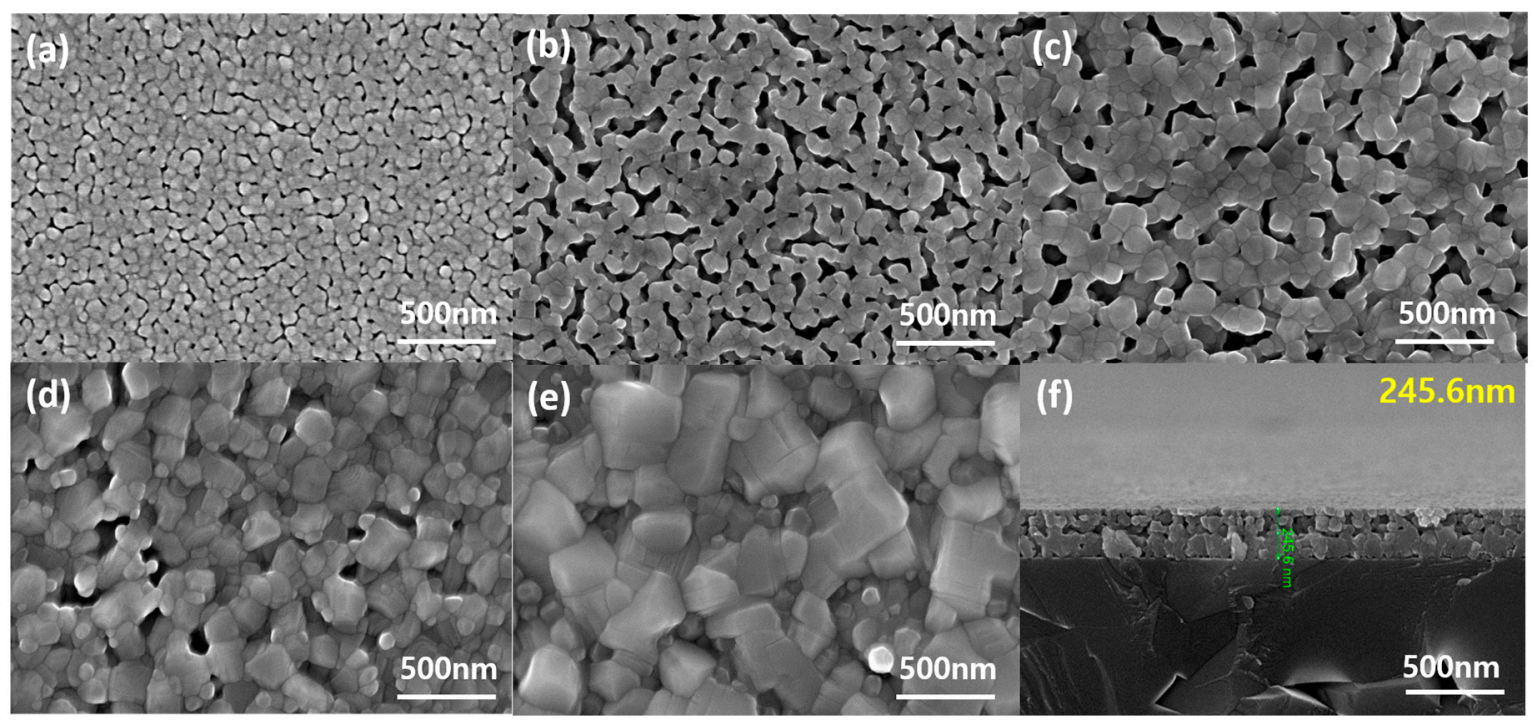

Figure 3. FE-SEM top view images of lanthanum nickel oxide (LNO) thin films sintered by a thermal technique at (a) $700{ }^{\circ} \mathrm{C},(\mathbf{b}) 800{ }^{\circ} \mathrm{C}$, (c) $900{ }^{\circ} \mathrm{C}$, (d) $1000{ }^{\circ} \mathrm{C}$, (e) $1100{ }^{\circ} \mathrm{C}$ and (f) cross-sectional view image of the LNO thin film sintered at $700^{\circ} \mathrm{C}$. 
Lanthanum nickel oxide (LNO) has a perovskite and Ruddlesden-Popper (RP) structure. As the sintering temperature increases in the perovskite crystal structure above $900^{\circ} \mathrm{C}$, it is transformed to the $\mathrm{RP}$ structure of $\mathrm{La}_{n+1} \mathrm{Ni}_{n} \mathrm{O}_{3 n+1}(n=3,2$, and 1). Ruddlesden-Popper structures consist of perovskite $\left(\mathrm{LaNiO}_{3}\right)$ and $\mathrm{LaO}$ layers. The structures emerge from the $\mathrm{La}_{4} \mathrm{Ni}_{3} \mathrm{O}_{10}(n=1)$ materials from the reaction of $\mathrm{LaNiO}_{3}$ with $\mathrm{NiO}$ and gradually transfer the phase in the direction of decreasing number $n(n=3$, 2, and 1) [34]. Figure 4 shows XRD patterns of the perovskite and RP crystallinity development of LNO thin films after thermal sintering in the 700 to $1100{ }^{\circ} \mathrm{C}$ temperature range. In Figure 4a, the XRD pattern indicates perovskite crystallinity development at a sintering temperature of around $700-900{ }^{\circ} \mathrm{C}$. The difference in the intensity of the perovskite crystal development peaks showed little difference among sintering temperatures. As the sintering temperature increased from 700 to $900{ }^{\circ} \mathrm{C}$, the intensity of the perovskite crystal development slightly increased. However, when the sintering temperature increased, nickel oxide $(\mathrm{NiO})$ peaks were expressed in addition to the perovskite crystalline peaks. The observed peak for $\mathrm{NiO}$ in the XRD pattern confirmed the phase transition from the perovskite to the RP structure. Figure $4 \mathrm{~b}$ confirms that the sintered material was transformed into $\mathrm{La}_{4} \mathrm{Ni}_{3} \mathrm{O}_{10}$ when sintered at 1000 and $1100{ }^{\circ} \mathrm{C}$.
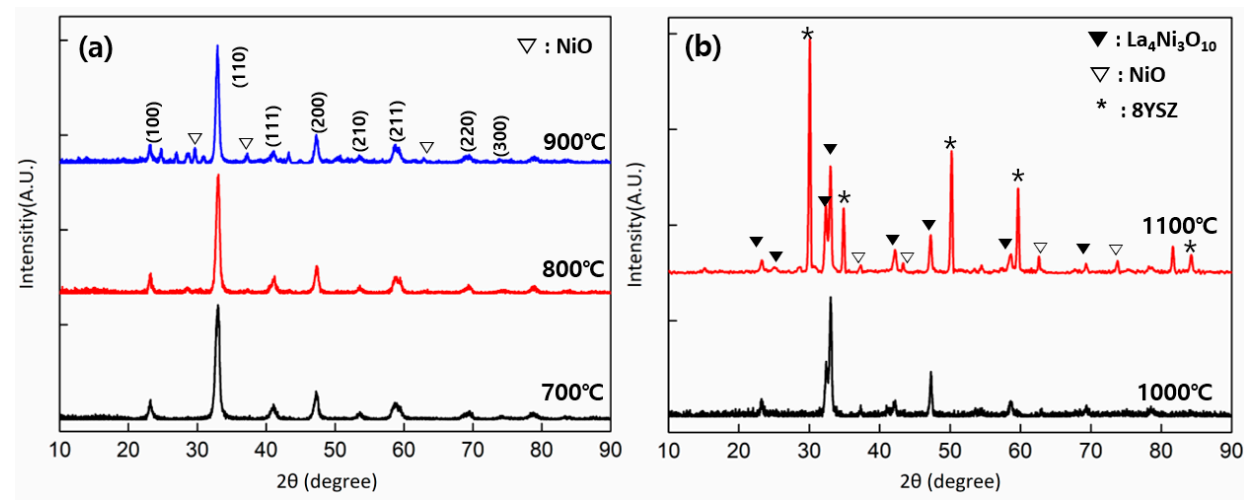

Figure 4. X-ray diffraction of patterns of perovskite $\mathrm{LaNiO}_{3}$ thin films sintered at (a) 700, 800, and $900{ }^{\circ} \mathrm{C}$, and (b) Ruddlesden-Popper (RP) structure sintered at 1000 and $1100{ }^{\circ} \mathrm{C}$.

The resistivity of thermally sintered LNO thin films was measured by the DC four-point probe method at room temperature, which measures the sheet resistance $(\Omega /$ square $)$ of thin films. The resistivity values of the thin films were calculated using the correction factor, sample size, and thickness of the layer. The change in the resistivity of the LNO thin films with changes in sintering temperature from 500 to $1100{ }^{\circ} \mathrm{C}$ is depicted in Figure 5. When sintering was carried out at $500{ }^{\circ} \mathrm{C}$, the LNO thin films had high resistivity, because the organics and residues were not completely decomposed, and perovskite crystallization was underdeveloped for the desired electrical property of the film. The lowest resistivity value of the LNO thin films was $6.26 \times 10^{-4}-6.8 \times 10^{-4} \Omega \cdot \mathrm{cm}$ in the sintering temperature range of 600 to $700{ }^{\circ} \mathrm{C}$. This temperature range is optimal for producing the lowest resistivity of LNO thin films. When the sintering temperature increased further, the resistivity tended to increase. As depicted in Figure $4 b$, the LNO perovskite structure phase transformed to the $\mathrm{RP}$ structure, indicating that the RP LNO thin films had lower electric conductivity than the perovskite structure. Therefore, the resistivity of LNO thin films gradually increased with the increasing thermal sintering temperature. 


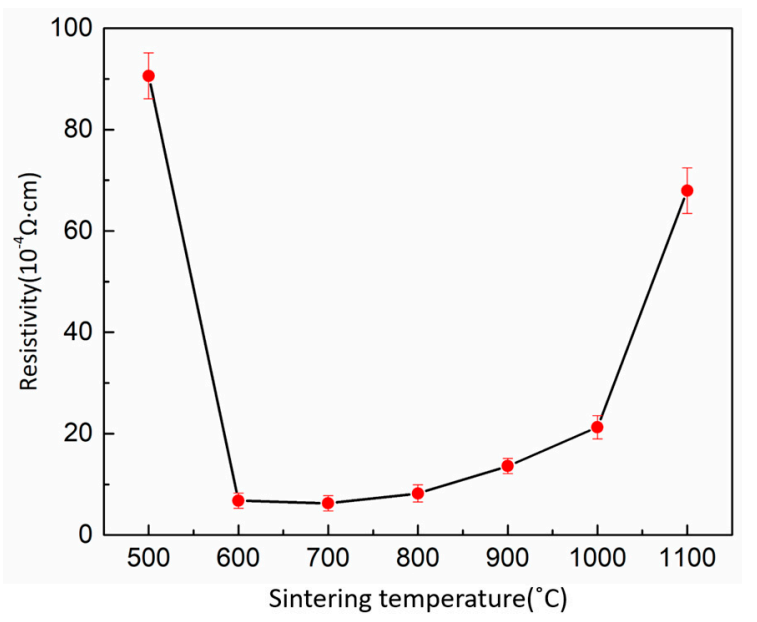

Figure 5. Resistivity of the thermally sintered $\mathrm{LaNiO}_{3}$ thin film with regard to sintering temperature.

To investigate the effects of flash light irradiation on LNO thin films, we analyzed the microstructure, crystal development, and resistivity of flash light-sintered LNO thin films compared to the results of the thermally sintered thin film. In the flash light-sintered LNO thin films, flash light sintering was controlled with the on and off times (ms), pulse number (\#) of light irradiation, and total energy density $\left(\mathrm{J} / \mathrm{cm}^{2}\right)$ conditions of the charged voltage. The flash light-sintering conditions were set as an on time of $30 \mathrm{~ms}$ for light irradiation and an off time of $80 \mathrm{~ms}$ of six pulsed irradiations. The total energy density of flash light sintering was in the 60 to $130 \mathrm{~J} / \mathrm{cm}^{2}$ range according to the on-off times, pulse conditions, and charged voltage. Similarly, FE-SEM and XRD analyses and electrical conductivity measurements were performed to characterize the flash light-sintered LNO thin films.

FE-SEM images of the flash light-sintered LNO films are shown in Figure 6. As depicted in Figure $6 \mathrm{f}$, the deposition process was carried out for an LNO thin film thickness of $248.1 \mathrm{~nm}$. The surface morphology of the flash light-sintered LNO thin films showed smaller nanopores and grain sizes at $60-80 \mathrm{~J} / \mathrm{cm}^{2}$, as shown in Figure 6a,b. Also, as the energy density increased to $130 \mathrm{~J} / \mathrm{cm}^{2}$, grain growth was observed and filled the nanopores. However, the grain size of the flash light-sintered LNO thin films was a little smaller than that of the thermally sintered films. In comparison with the thermally sintered microstructure, there are few differences in the microstructure of the grain growth. The XRD analysis was conducted to compare the perovskite crystal development of the flash light-sintered films with those thermally sintered. Figure 7 presents the XRD pattern of flash light-irradiated perovskite LNO thin films at energy densities of 60,80 , and $100 \mathrm{~J} / \mathrm{cm}^{2}$, respectively. The XRD patterns show that the flash light-sintered LNO thin films have equal perovskite crystallinity, regardless of the energy condition. The XRD pattern of light-sintered LNO thin films did not produce a secondary phase at 60 to $100 \mathrm{~J} / \mathrm{cm}^{2}$. The XRD analysis showed that flash light sintering can produce perovskite crystallinity and show similar peak intensity to that of thermal sintering. 




Figure 6. FE-SEM top view images of LNO thin films sintered by flash light irradiation at (a) $60 \mathrm{~J} / \mathrm{cm}^{2}$, (b) $80 \mathrm{~J} / \mathrm{cm}^{2}$, (c) $100 \mathrm{~J} / \mathrm{cm}^{2}$, (d) $120 \mathrm{~J} / \mathrm{cm}^{2}$, and (e) $130 \mathrm{~J} / \mathrm{cm}^{2}$ and (f) cross-sectional view image of the LNO thin film sintered at $60 \mathrm{~J} / \mathrm{cm}^{2}$.

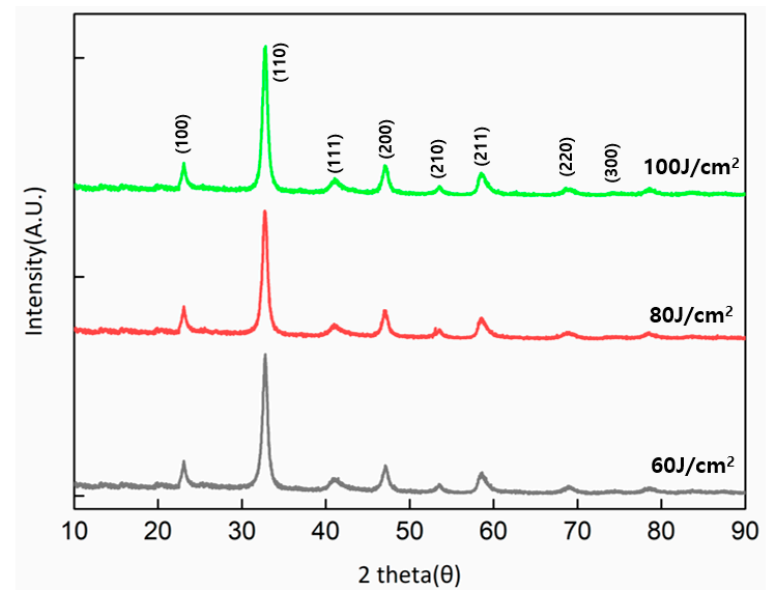

Figure 7. X-ray diffraction patterns of perovskite $\mathrm{LaNiO}_{3}$ thin films sintered at 60,80 and $100 \mathrm{~J} / \mathrm{cm}^{2}$.

For more accurate comparative analysis of the thermal annealing and the flash light processes, the resistivity of the flash light-sintered LNO thin films was measured by the DC four-point probe at room temperature, which is the same measurement condition as the thermally sintered samples. The change in the resistivity of the LNO thin films with the change in energy density is depicted in Figure 8a. Flash light sintering was carried out by changing the total energy density $\left(\mathrm{J} / \mathrm{cm}^{2}\right)$ as the difference of charge voltage with a fixed on time, off time, and number of pulses. Compared with thermally sintered thin film resistivity, that of flash light-sintered film has a similar tendency. However, when irradiated as energy density increased from 50 to $60 \mathrm{~J} / \mathrm{cm}^{2}$, the resistivity value sharply decreased from $201.31 \times 10^{-4}$ to $10.73 \times 10^{-4} \Omega \cdot \mathrm{cm}$. Although the energy density increased, the resistivity remained constant. When the irradiation energy was raised to $100 \mathrm{~J} / \mathrm{cm}^{2}$, the resistivity increased. These results indicate that resistivity should consider the effects of surface microstructure, crystallinity, and thin film thickness.

In the analysis of XRD results, it was observed that changes in peak intensity or other phases did not occur at 60,80 , or $100 \mathrm{~J} / \mathrm{cm}^{2}$. Therefore, the slight difference of the resistivity value of the thermally sintered and flash-sintered thin films appears to be due to the differences in the microstructure and thickness of the films. The sheet resistance of the thin films tends to gradually decrease as the thickness 
of the thin film increases and converges to a minimum resistance at about $230-250 \mathrm{~nm}$. The spin-coated layers are very thin after one deposition cycle. The change in the thickness of the thin film with the number of spin-coating cycles and the change in resistivity in accordance with thickness are shown in Figure 8b. FE-SEM cross-sectional images show a gradual increase of film thickness as the number of spin-coating processes increases in Figure 9. It was necessary to laminate the deposited films several times to achieve a thickness of $230 \mathrm{~nm}$. However, in certain cases, the thickness is slightly increased, rather than increasing linearly, or a slightly thinner layer may be deposited. For this reason, a change in resistivity may be observed.
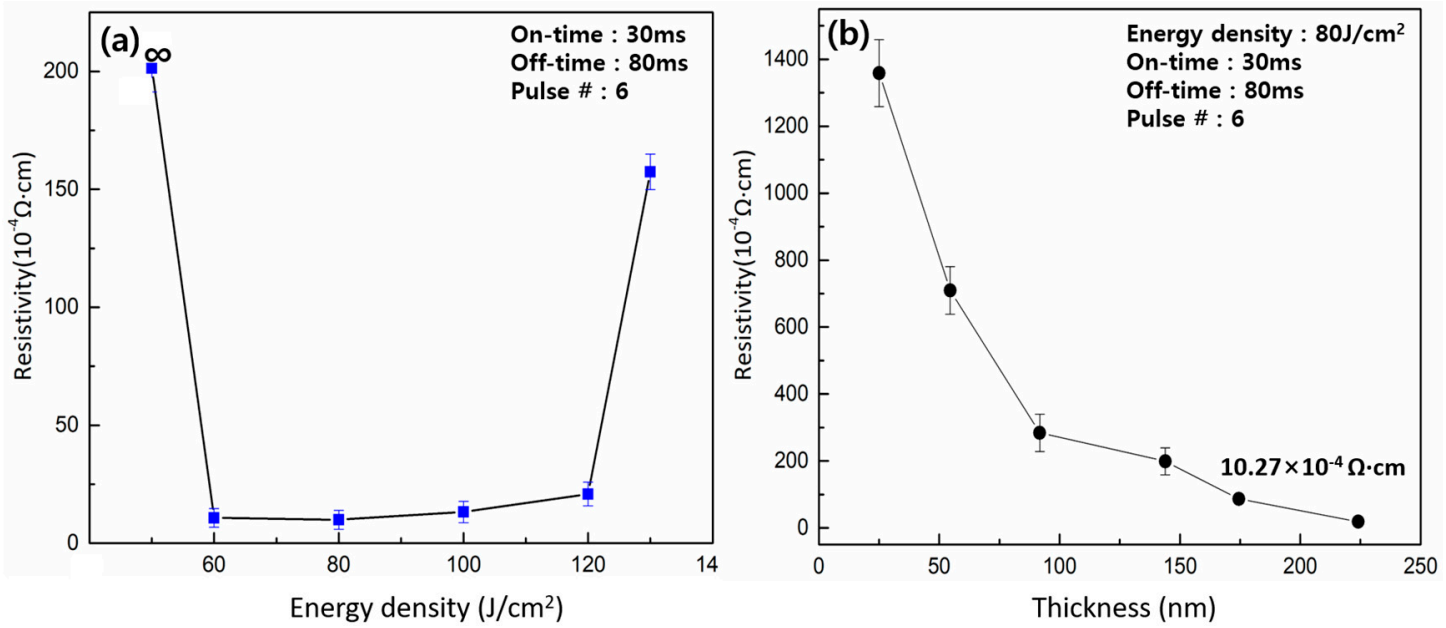

Figure 8. Resistivity of the flash light-sintered $\mathrm{LaNiO}_{3}$ thin film with regard to (a) energy density and (b) thickness.

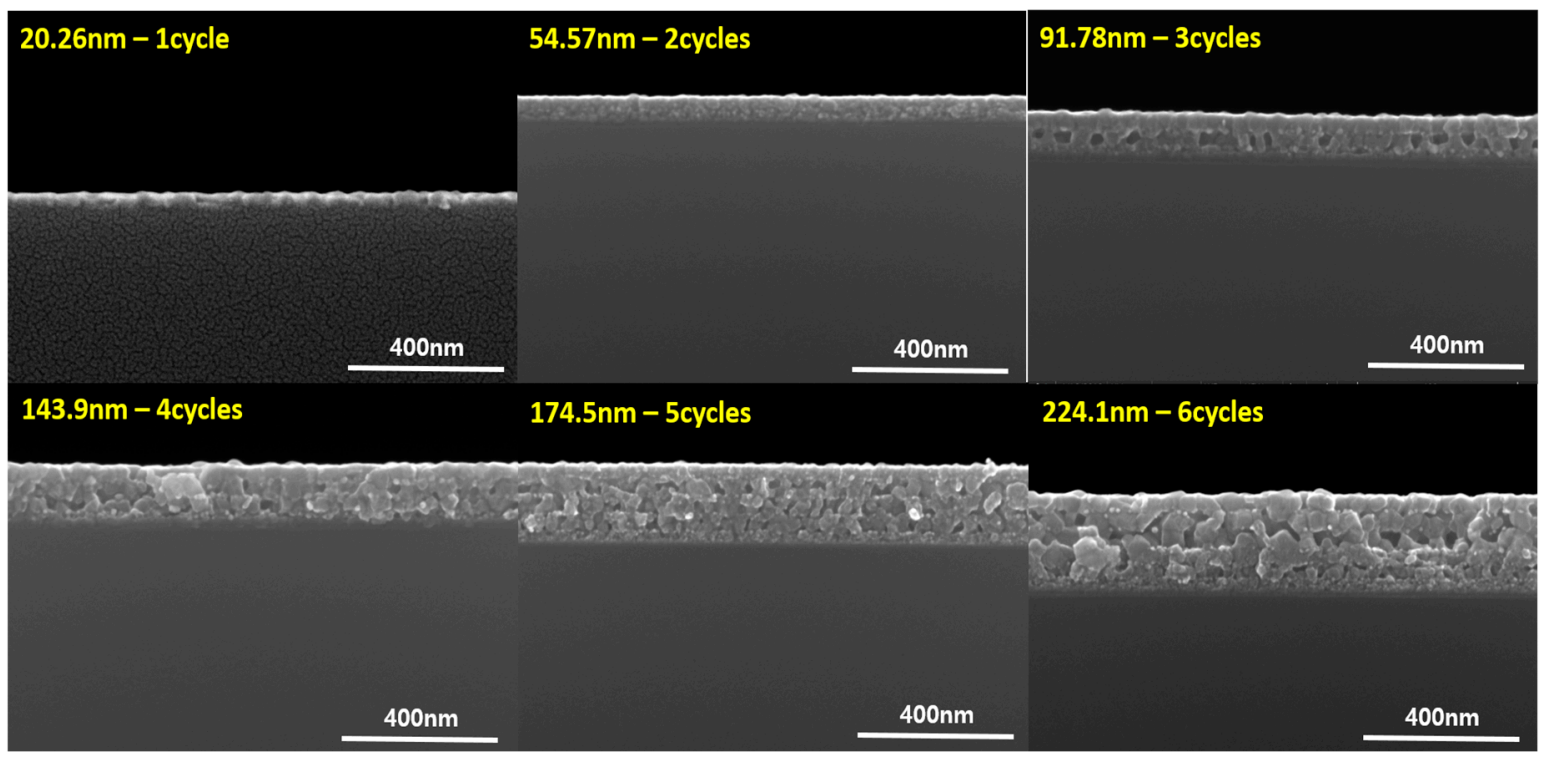

Figure 9. Thickness of the flash light-sintered LNO films according to spin coating cycle.

The X-ray diffraction analysis results are shown in Figure 10. These show that the perovskite crystalline structure of the LNO thin films are equally developed when the thermal $\left(700-900{ }^{\circ} \mathrm{C}\right)$ and flash light $\left(60-100 \mathrm{~J} / \mathrm{cm}^{2}\right)$ sintering proceeds. All of the results have the same perovskite crystallinity, except that $\mathrm{NiO}$ peaks were developed at a thermal sintering temperature of $900{ }^{\circ} \mathrm{C}$. Although there are slight differences in the peak intensity at (110), they have approximately similar peak intensity when comparing thermal sintering with flash light sintering. 


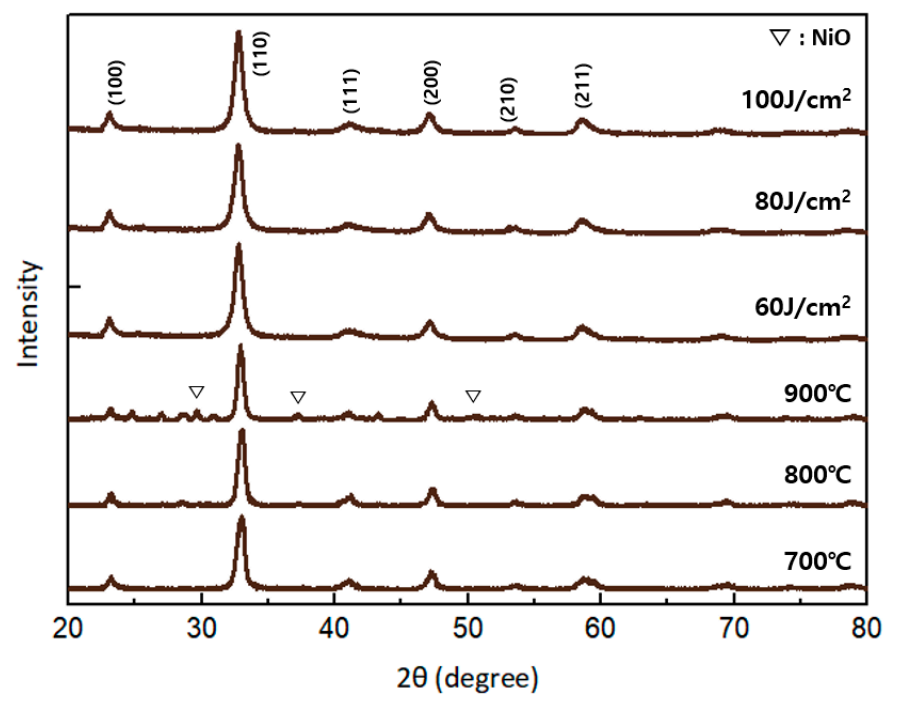

Figure 10. The X-ray diffraction analysis comparing thermal and flash light sintering of the LNO thin films.

The resistivity of thermally sintered and flash light-sintered LNO thin films is depicted in Figure 11. The resistivity of thermal and flash light sintering was measured at three points, in which each used the four-point probe. The minimum resistivity was $6.26 \times 10^{-4}$ and $9.923 \times 10^{-4} \Omega \cdot \mathrm{cm}$ for thermal and flash light sintering, respectively. Although the resistivity of thermal sintering was smaller than that of flash light sintering, the values are similar.

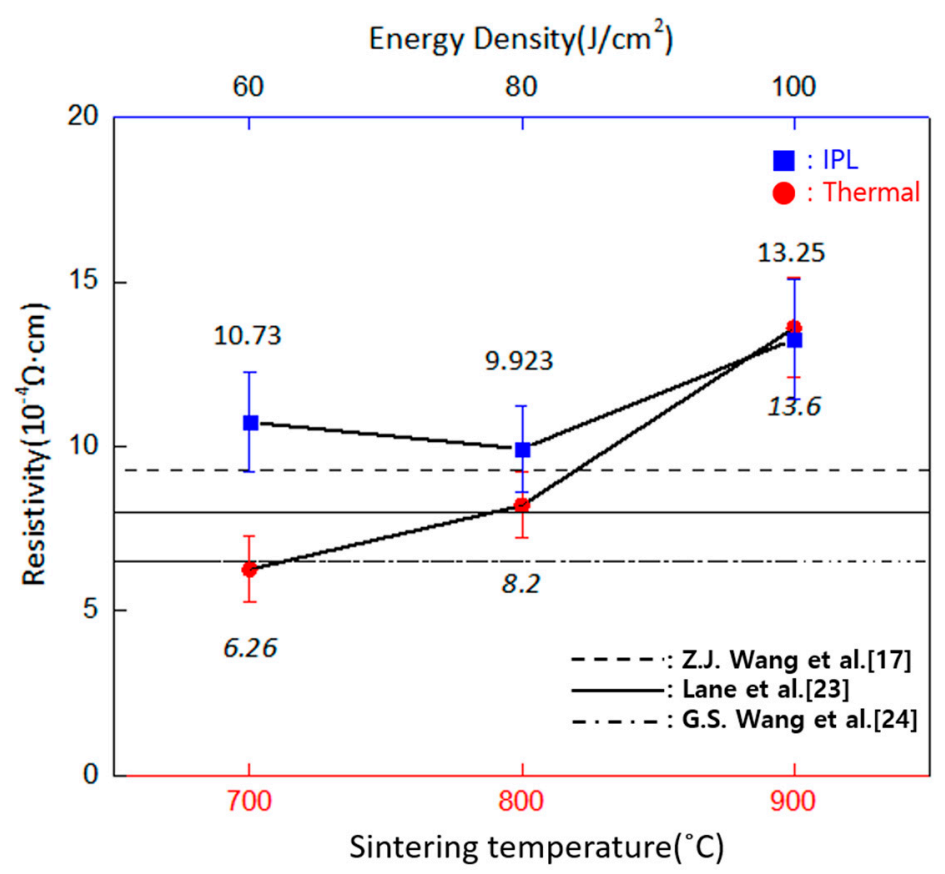

Figure 11. Resistivity of the sintered LNO films with regard to sintering temperature and irradiation energy density.

These results demonstrated that flash light sintering effects could be achieved in a short time and with a simple process. In this study, we confirmed the feasibility and practicality of the flash light-sintering method through perovskite crystal development based on XRD patterns and electric conductivity measurements. Furthermore, it is anticipated that an energy device will be manufactured using flash light sintering after optimization studies are conducted for the light sintering conditions. 


\section{Conclusions}

In this study, we demonstrated a novel flash light sintering method for chemical solution-deposited LNO thin films compared with thermally sintered LNO thin films characterized by FE-SEM, XRD, and four-point probe. The fabricated LNO thin films should have electrical conductivity and be able to function as an electron-conducting composite for various applications, including energy devices with a uniform film quality. The resistivity values of the thermally and flash light-sintered LNO thin films under each of the sintering conditions are shown in Figure 11. The resistivity of the LNO thin films after sintering have similar values at each of the three points. The lowest resistivity of the thermally and light-sintered LNO thin films is $6.26 \times 10^{-4}$ and $9.923 \times 10^{-4} \Omega \cdot \mathrm{cm}$, respectively. Although the thermally-sintered LNO thin films have lower resistivity than light-sintered films, they have approximately the same resistivity values. Therefore, the results of this study indicate that the flash light-sintering method significantly reduces the sintering time from tens of hours to milliseconds for the fabrication of perovskite LNO thin films.

Author Contributions: Experimental measurements have been conducted by J.P. Analysis and interpretation of the results as well as conclusions have been conducted by all the co-authors. The manuscript has been written by J.P. with the revision and approval by the others co-authors and Y.-B.K. participated in the discussions and helped to revise it as supervisor.

Funding: This research was funded by the Korea Institute of Energy Technology Evaluation and Planning (KETEP) from the Ministry of Trade, Industry \& Energy, Republic of Korea (No. 201700000003242) and the Basic Science Research Program through the National Research Foundation of Korea (NRF) funded by the Ministry of Education (2012R1A6A1029029).

Acknowledgments: This research was funded by the Korea Institute of Energy Technology Evaluation and Planning (KETEP) from the Ministry of Trade, Industry \& Energy, Republic of Korea (No. 201700000003242) and the Basic Science Research Program through the National Research Foundation of Korea (NRF) funded by the Ministry of Education (2012R1A6A1029029).

Conflicts of Interest: The authors declare no conflict of interest.

\section{References}

1. Cohen, R.E. Origin of ferroelectricity in perovskite oxides. Nature 1992, 358, 136-138. [CrossRef]

2. Maeno, Y.; Hashimoto, H.; Yoshida, K.; Nishizaki, S.; Fujita, T.; Bednorz, J.G.; Lichtenberg, F. Superconductivity in a layered perovskite without copper. Nature 1994, 372, 532-534. [CrossRef]

3. Bonanos, N.; Knight, K.S.; Ellis, B. Perovskite solid electrolytes: Structure, transport properties and fuel cell applications. Solid State Ion. 1995, 79, 161-170. [CrossRef]

4. Li, A.; Wu, D.; Liu, Z.; Ge, C.; Liu, X.; Chen, G.; Ming, N. TEM and AFM study of perovskite conductive $\mathrm{LaNiO}_{3}$ films prepared by metalorganic decomposition. Thin Solid Films 1998, 336, 386-390. [CrossRef]

5. Suzuki, H.; Miwa, Y.; Naoe, T.; Miyazaki, H.; Ota, T.; Fuji, M.; Takahashi, M. Orientation control and electrical properties of PZT/LNO capacitor through chemical solution deposition. J. Eur. Ceram. Soc. 2006, 26, 1953-1956. [CrossRef]

6. Wei, B.; Lü, Z.; Huang, X.; Miao, J.; Sha, X.; Xin, X.; Su, W. Crystal structure, thermal expansion and electrical conductivity of perovskite oxides $\mathrm{Ba}_{x} \mathrm{Sr}_{1-x} \mathrm{Co}_{0.8} \mathrm{Fe}_{0.2} \mathrm{O}_{3-\delta}(0.3 \leq x \leq 0.7)$. J. Eur. Ceram. Soc. 2006, 26, 2827-2832. [CrossRef]

7. Konysheva, E.; Irvine, J.T. Evolution of conductivity, structure and thermochemical stability of lanthanum manganese iron nickelate perovskites. J. Mater. Chem. 2008, 18, 5147-5154. [CrossRef]

8. Jiang, J.J.; Li, D.; Li, S.J.; Wang, Z.H.; Wang, Y.; He, J.; Liu, W.; Zhang, Z.D. Electromagnetic wave absorption and dielectric-modulation of metallic perovskite lanthanum nickel oxide. RSC Adv. 2015, 5, 14584-14591. [CrossRef]

9. Yang, W.S.; Noh, J.H.; Jeon, N.J.; Kim, Y.C.; Ryu, S.; Seo, J.; Seok, S.I. High-performance photovoltaic perovskite layers fabricated through intramolecular exchange. Science 2015, 348, 1234-1237. [CrossRef]

10. Schwartz, R.W. Chemical solution deposition of perovskite thin films. Chem. Mater. 1997, 9, $2325-2340$. [CrossRef] 
11. Jun, A.; Kim, J.; Shin, J.; Kim, G. Perovskite as a cathode material: A review of its role in solid-oxide fuel cell technology. ChemElectroChem 2016, 3, 511-530. [CrossRef]

12. Chroneos, A.; Vovk, R.V.; Goulatis, I.L.; Goulatis, L.I. Oxygen transport in perovskite and related oxides: A brief review. J. Alloy. Compd. 2010, 494, 190-195. [CrossRef]

13. Richter, J.; Holtappels, P.; Graule, T.; Nakamura, T.; Gauckler, L.J. Materials design for perovskite SOFC cathodes. Monatsh. Chem. 2009, 140, 985-999. [CrossRef]

14. Skinner, S.J. Recent advances in Perovskite-type materials for solid oxide fuel cell cathodes. Int. J. Inorg. Mater. 2001, 3, 113-121. [CrossRef]

15. Monterrubio-Badillo, C.; Ageorges, H.; Chartier, T.; Coudert, J.F.; Fauchais, P. Preparation of $\mathrm{LaMnO}_{3}$ perovskite thin films by suspension plasma spraying for SOFC cathodes. Surf. Coat. Technol. 2006, 200, 3743-3756. [CrossRef]

16. Fernandes, J.D.G.; Melo, D.M.A.; Zinner, L.B.; Salustiano, C.M.; Silva, Z.R.; Martinelli, A.E.; Cerqueira, M.; Alves Júnior, C.; Longo, E.; Bernardi, M.I.B. Low-temperature synthesis of single-phase crystalline $\mathrm{LaNiO}_{3}$ perovskite via Pechini method. Mater. Lett. 2002, 53, 122-125. [CrossRef]

17. Matumoto, Y.; Yoneyama, H.; Tamura, H. A new catalyst for cathodic reduction of oxygen: Lanthanum nickel oxide. Chem. Lett. 1975, 4, 661-662. [CrossRef]

18. Chen, S.T.; Wang, G.S.; Zhang, Y.Y.; Yang, L.H.; Dong, X.L. Orientation control growth of lanthanum nickelate thin films using chemical solution deposition. J. Am. Ceram. Soc. 2007, 90, 3635-3637. [CrossRef]

19. Matavž, A.; Kovač, J.; Čekada, M.; Malič, B.; Bobnar, V. Enhanced electrical response in ferroelectric thin film capacitors with inkjet-printed $\mathrm{LaNiO}_{3}$ electrodes. Appl. Phys. Lett. 2018, 113, 012904. [CrossRef]

20. Biswas, M. Synthesis of single phase rhombohedral $\mathrm{LaNiO}_{3}$ at low temperature and its characterization. J. Alloy. Compd. 2009, 480, 942-946. [CrossRef]

21. Wang, G.S.; Rémiens, D.; Dogheche, E.; Herdier, R.; Dong, X.L. Fabrication and electrical properties of lead zirconate titanate thick films on Si substrate by using lanthanum nickelate buffer layer. J. Am. Ceram. Soc. 2006, 89, 3417-3420. [CrossRef]

22. Suzuki, H.; Naoe, T.; Miyazaki, H.; Ota, T. Deposition of highly oriented lanthanum nickel oxide thin film on silicon wafer by CSD. J. Eur. Ceram. Soc. 2007, 27, 3769-3773. [CrossRef]

23. Duan, Z.; Cui, Y.; Yang, Z.; Li, K.; Wan, Y.; Lu, Z.; Xie, Y.; Zhang, J. Growth of highly c-axis oriented $\mathrm{LaNiO}_{3}$ films with improved surface morphology on Si substrate using chemical solution deposition and rapid heat treatment process. Ceram. Int. 2018, 44, 695-702. [CrossRef]

24. Lane, P.A.; Crosbie, M.J.; Wright, P.J.; Donohue, P.P.; Hirst, P.J.; Reeves, C.L.; Williams, D.J. The metal-organic chemical vapor deposition of lanthanum nickelate electrodes for use in ferroelectric devices. Chem. Vap. Depos. 2003, 9, 87-92. [CrossRef]

25. Wang, G.S.; Zhao, Q.; Meng, X.J.; Chu, J.H.; Remiens, D. Preparation of highly (100)-oriented $\mathrm{LaNiO}_{3}$ nanocrystalline films by metalorganic chemical liquid deposition. J. Cryst. Growth 2005, 277, 450-456. [CrossRef]

26. Hwang, K.S.; Min, S.S.; Park, Y.J. Formation of highly-oriented and polycrystalline lanthanum nickelate films by a spin coating-pyrolysis process. Surf. Coat. Technol. 2001, 137, 205-208. [CrossRef]

27. Park, J.S.; Bae, J.; Hong, S.; Kim, Y.B. Superior $\mathrm{La}_{1-x} \mathrm{Sr}_{x} \mathrm{CoO}_{3-\delta}$ ceramic electrode fabrication by MOCSD for low-temperature SOFC application. Surf. Coat. Technol. 2017, 311, 157-163. [CrossRef]

28. Dharmadasa, R.; Dharmadasa, I.M.; Druffel, T. Intense pulsed light sintering of electrodeposited CdS thin films. Adv. Eng. Mater. 2014, 16, 1351-1361. [CrossRef]

29. Niittynen, J.; Sowade, E.; Kang, H.; Baumann, R.R.; Mäntysalo, M. Comparison of laser and intense pulsed light sintering (IPL) for inkjet-printed copper nanoparticle layers. Sci. Rep. 2015, 5, 8832. [CrossRef]

30. Oh, G.H.; Hwang, H.J.; Kim, H.S. Effect of copper oxide shell thickness on flash light sintering of copper nanoparticle ink. RSC Adv. 2017, 7, 17724-17731. [CrossRef]

31. Moon, C.J.; Kim, I.; Joo, S.J.; Chung, W.H.; Lee, T.M.; Kim, H.S. Flash light sintering of ag mesh films for printed transparent conducting electrode. Thin Solid Films 2017, 629, 60-68. [CrossRef]

32. Wu, G.; Ruan, K.; Liang, T.; Chen, X.; Bao, D. Preparation and conductive properties of neodymium-doped lanthanum nickelate thin films by chemical solution deposition method. Thin Solid Films 2009, 517, 1563-1566. [CrossRef] 
33. Park, J.S.; Kim, Y.B. Synthesis and characterization of nanoporous strontium-doped lanthanum cobaltite thin film using metal organic chemical solution deposition. Thin Solid Films 2016, 599, 174-178. [CrossRef]

34. Ryll, T.; Reibisch, P.; Schlagenhauf, L.; Bieberle-Huetter, A.; Döbeli, M.; Rupp, J.L.; Gauckler, L.J. Lanthanum nickelate thin films deposited by spray pyrolysis: Crystallization, microstructure and electrochemical properties. J. Eur. Ceram. Soc. 2012, 32, 1701-1709. [CrossRef]

(C) 2019 by the authors. Licensee MDPI, Basel, Switzerland. This article is an open access article distributed under the terms and conditions of the Creative Commons Attribution (CC BY) license (http://creativecommons.org/licenses/by/4.0/). 